\title{
The Potential of Temporary Immersion Bioreactors (TIBs) in Meeting Crop Production Demand in Nigeria
}

\author{
Paul Terwase Lyam (Corresponding author) \\ National Center for Genetic Resources and Biotechnology (NACGRAB) \\ Federal Ministry of Science \& Technology, P.M.B 5382 \\ Moor Plantation, Apata - Ibadan, Oyo State, Nigeria \\ Tel: 234-806-350-2051_E-mail:pauliam003@yahoo.com \\ Mutah L. Musa \\ National Center for Genetic Resources and Biotechnology (NACGRAB) \\ Federal Ministry of Science \& Technology, P.M.B 5382 \\ Moor Plantation, Apata - Ibadan, Oyo State, Nigeria. \\ $\&$
}

Universiti Teknologi Malaysia, 81310 UTM Skudai, Johor Bahru, Johor, Malaysia

Tel: 60-1-6270-4225 E-mail: mutahlm@yahoo.co.uk

Zainab O. Jamaleddine

National Center for Genetic Resources and Biotechnology (NACGRAB)

Federal Ministry of Science \& Technology, P.M.B 5382

Moor Plantation, Apata - Ibadan, Oyo State, Nigeria

Tel: 234-805-856-7113Ｅ-mail: glizzy00@yahoo.com

Ugochukwu Anthony Okere

National Center for Genetic Resources and Biotechnology (NACGRAB)

Federal Ministry of Science \& Technology, P.M.B 5382

Moor Plantation, Apata - Ibadan, Oyo State, Nigeria

Tel: 234-803-604-2204Ｅ-mail: oaugoton@yahoo.com

Wasiu T. Odofin

National Center for Genetic Resources and Biotechnology (NACGRAB) 
Federal Ministry of Science \& Technology, P.M.B 5382

Moor Plantation, Apata - Ibadan, Oyo State, Nigeria

Tel: 234-803-628-1963Ｅ-mail: wodofin@yahoo.co.uk

Aragon Carlos

Laboratory for Plant Cell and Tissue Culture,

Centro de Bioplantas, Universidad de Ciego de Ávila, Cuba

Received: December 10, 2011 Accepted: December 27, 2011

doi:10.5296/jbls.v3i1.1156 URL: http://dx.doi.org/10.5296/jbls.v3i1.1156

\begin{abstract}
Micropropagation, popularly known for large-scale clonal propagation, is the first major and widely accepted practical application of plant biotechnology. The commercial utility of conventional micropropagation of important crop species is limited as a result of the large numbers needed annually to start up new farms in addition to high production costs. These result primarily from high labour cost, low multiplication rate or long duration of multiplication before plantlets are taken to the field, and poor survival rates resulting from contamination risks and during acclimatization. All of these constitute a major setback in the use of Micropropagation for scaling up of the several economic species for commercialization. Temporary Immersion Bioreactor system (TIBs) is a relatively recent micropropagation procedure that employs the use of automated gadgets to control rapid multiplication of plant cultures under adequate conditions. TIBs provide a more precise control of the adequate conditions (gaseous exchange, illumination etc.) required by plants for growth, development and survival than the conventional culture vessels. This bioreactor system incorporates a number of features specifically designed to simplify its operation and reduce production costs. The set-up consists of two vessels, one for the plantlets and the other one for the liquid culture media coupled together through a perforated rubber tubing that permits the flow of the liquid media from one vessel to the other. TIBs consist of three main phases: Multiplication, Elongation and Rooting phase. Plantlets propagated in TIBs have better performance than those propagated by conventional methods of micropropagation. This is as a result of a better handling of the in vitro atmosphere and the nutrition. TIBs provide a rapid and efficient plant propagation system for many agricultural and forestry species, utilizing liquid media to avoid intensive manual handling. In addition to diminishing production costs regarding labour force, Temporary Immersion Bioreactors save energy, augment micropropagation productivity and efficiency.
\end{abstract}

Keywords: Temporary Immersion Bioreactors, Scale-up, Micropropagation 


\section{Introduction}

New contributions to in vitro techniques for plant propagation in the last decade has simplified micropropagation technology and at the same time open up new avenues of challenges. It took scientists and researchers a number of steps and lots of effort to arrive at the various micropropagation protocols and techniques, routinely applied today in most laboratories. Research have over time, risen from a myriad of challenges to what appears to be less challenging but the mystery behind this is at every new level, there is a new encounter that limits the adequate achievement of the new task.

Plant regeneration in vitro is dependent on the manipulation of the inorganic and organic constituents in the medium, as well as the type of explant and the species. In most plant species, successful regeneration from the callus or directly from the explants takes place after a series of subcultures on various media, in a sequence which is often specific to the species, variety, or the newly introduced genotype. The determining factors are the combination of the concentration in relation to medium volume and the composition of growth promoting and retarding regulators in the medium, the physiological status and competence of the cells and their capability for morphogenetic expression (Christianson, 1985; 1987).

In micropropagation, all plant somatic cells once isolated and cultured in vitro are capable of expressing totipotency. Regeneration is potentiated through two morphogenic pathways:

Organogenesis which is the formation of unipolar organs and Somatic embryogenesis which is the production of somatic embryos with a root and a shoot meristem (Steward et al., 1970; Ammirato et al., 1985). After many decades of research and development, conventional micropropagation techniques are still not always reliable. The commercial utility of conventional micropropagation of most important crop species is limited and scaling-up is not always easy. Nevertheless, their application in horticulture, agriculture, and forestry is currently still expanding worldwide. In order to overcome the problems of conventional micropropagation, protocols have been proposed using bioreactors and liquid medium (Tautorus et al., 1995; Weathers et al., 1989; Takayama and Akita, 1994; Teisson and Alvard, 1995). Automation, using a bioreactor, is one of the most effective ways to reduce the costs of micropropagation (Aitken-Christie et al., 1995; Levin et al., 1998). In temporary immersion bioreactors, the cultures are immersed in the medium, for a preset duration at specified intervals. A typical design, utilizes two vessels (plastic or glass) of which one holds the liquid medium and the other the cultures (Adelberg and Simpson, 2002). Temporary immersion bioreactors are simple and cost effective to run. Consequently, a number of commercial micropropagation laboratories have begun to integrate these systems into their production procedures. Temporary Immersion Bioreactors (TIBs) generally reduces some problems usually encountered in permanent liquid cultures such as hyperhydricity, poor quality of propagules, and necessity of transplanting on a solid medium in the elongation and/or rooting stage. In comparison with conventional micropropagation on semisolid medium, the TIB provides a superior mass balance. Indeed in the latter comparison the proliferation rate is higher, labor efficiency is improved and, as a consequence, the cost is reduced (Teisson and Alvard, 1995; Escalona et al., 1999; Etienne et al., 2006). Recently, the effect of environmental 


\section{Macrothink}

conditions, such as nutrient supply and composition of the internal atmosphere in the culture vessel, on the physiology of some species in the recipient for automated temporary immersion system (RITA) has been reported (Martre et al., 2001; Escalona et al., 2003). This definition of physiological requirements of explants and eco-physiological characterization of the bioreactor environment has contributed immensely to facilitate an increase in plant quality. This paper reviews the potential benefits and importance of TIBs; and how it can be applied as a tool for scaling up economically important species to enhance food security in Nigeria.

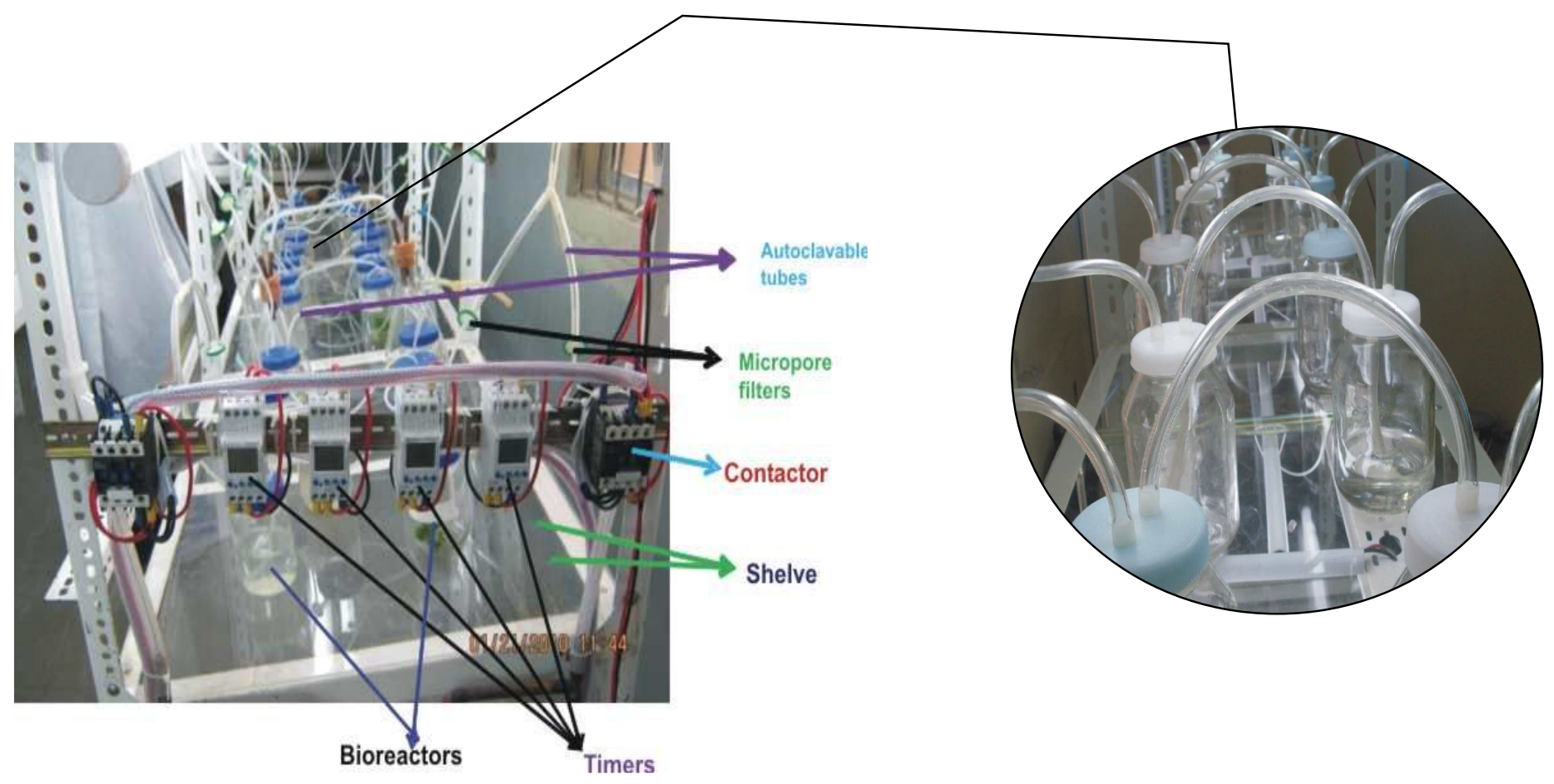

Figure 1. Temporary immersion bioreactor set up at NACGRAB.

\subsection{Importance of TIBs technology to national development.}

Modern biotechnology has put the micropropagation industry on the verge of exciting new breakthroughs. It offers improvements in virtually every area of crop production and utilization, with potential benefits to agriculture, the food industry, consumers and the environment. As the world's population continues to grow, it is anticipated that there could be many mouths to feed in the next few decades. The advances made possible through micropropagation (TIBs) will be essential to meet global food needs by increasing the yield, quality and quantity of crops available to farmers. TIBs offer further benefits in form of non-food crops. Through mass propagation of specific economic species, it will be possible to arrest desertification, soil erosion in affected areas and also increase industrial crop production as renewable sources of medicines, industrial chemicals, fuels etc. They offer potential benefits to the commercial farmers, industries, public, research scientists and students. The potential benefits of TIBs are summarized below.

- Mass propagation of agronomic food crops (food security). All year round production and supply of planting materials to farmers. 
- Scaling up of the production of specific crops for industrial use (A step towards commercialization) e.g pineapple juice.

- Mass propagation of economic tree species (e.g Eucalyptus spp., Adzadiracta indica - Neem, Accacia senegalensis - Gum Arabic) for addressing environmental problems like desertification and erosion.

- Job creation.

- Inspire collaborations among institutions on specific projects.

\subsection{Apparatus for setting up TIBs.}

TIBs technology requires advance automation procedure and as such setting up will require a number of equipment with unique specification and functions, proficiency in operation techniques and expertise. The knowledge about the interactions between plant physiology and the physical parameters in the bioreactor design is very crucial as lack of this knowledge will affect the efficient use and sustainability of the technology. At the National Centre for Genetic Resources and Biotechnology (NACGRAB), Ibadan, Nigeria, the following components have been acquired and utilized in setting up TIBs.

\subsubsection{Oil Free Compressor}

The oil free air compressor uses a motorized rotor to compress air. The oil free compressor is used in this system because entrained oil carry-over will interfere with the proper functioning of the Temporary Immersion System (TIS), as it could be a likely source of contamination.

\subsubsection{PVC tubes}

Tubes of varying sizes are used in this system as the channel for the transfer of compressed air between the compressor and the bioreactor vessels. The larger $(0.5 \mathrm{~mm})$ diameter tubing are to connect from the solenoid valve and terminate at the ' $\mathrm{T}$ ' connectors, the medium sized $(0.35 \mathrm{~mm}) \mathrm{pvc} / \mathrm{silicon}$ tubing to connect from the ' $\mathrm{T}$ ' connector to one end of the micropore filter. The smaller PVC/silicon tubing are connected from the filter to the bioreactor vessel and also interconnects the bioreactor vessels. The need to maintain sterility at this stage mandates the use of autoclaveable tubings. This is to allow repetitive use of tubing.

\subsection{3 ' $\mathrm{T}$ ' connectors}

At the initial stage of this project the use of copper ' $T$ ' connectors was used but there was a need to extend the ducts by welding to make it suitable. Later in the life of the project, the use of ready-made brass ' $\mathrm{T}$ ' connectors that fitted suitably into the Temporary Immersion System (TIS) was employed. Some of the factors to consider in the choice of the material for a ' $\mathrm{T}$ ' connector are its ability to withstand high pressure and resistance to corrosion (rusting).

\subsubsection{Hydrophobic micro pore filters (membrane)}

These are sterilizing grade filters with $0.22 \mu \mathrm{m}$ permeability that provides a sterility assurance, high flow rate and throughput (fig3). It is used in the system for filtration of the air coming from the compressor; this membrane serves as a sieve to eliminate contaminants and 
microorganisms, as well addressing the need to remove hydrocarbons ingested from the ambient.

\subsubsection{Clips}

In instances where deemed necessary clips are used to fasten the ends of the tubing. This serves in preventing disconnection during flow.

\subsubsection{Solenoid valve}

A solenoid valve is an electromechanical device which consists of two main parts as the name implies a solenoid and a valve. The solenoid converts electrical energy to mechanical energy, which in turn opens and closes the valve. The solenoid valve is controlled by an electric current, the solenoid creates a controlled magnetic field when electrical current passes through it causing the valve to open or close. It is mainly used to control air flow in the TIS.

\subsubsection{Programmable timer}

An electronic timer is used to control the sequence of an event or process. The programmable timer is used in TIS to control the flow of electric current into the solenoid valves.

\subsubsection{Barometer}

This is used to control the air pressure within the tank and regulate the outlet pressure.

\subsubsection{Shelves}

This is the mainframe on which the TIS is built. It comprises of the stand and the required number of layers. The layers are either of a perforated material or transparent sheets.

\subsubsection{Bioreactor vessels}

These are bottles usually made of glass or plastic having a volume between 0.5 to 5.0 liters. It is provided with a securing cover that can be opened for the replacement of media and removal of plants as may be required. Two holes are perforated on the cover to serve as inlet/outlet to air and the media tubing.

\subsubsection{Electrical accessories}

This will include electrical fittings, cables and insulators mainly for illumination. Lighting is very important in TIS as it permits the occurrence of some metabolic activities such as photosynthesis.

\section{Operational Mechanism}

This system requires steady power supply for its successful operation. The air compressor is powered until the 25 liters capacity tank (as applied in this case study) is filled with air at a pressure of 8 bar which could be regulated according to user's requirement. The outlet pressure is set to 1.5 bar taking into consideration important factors such as the air travelling distance, size and number of vessels in the system. The air is let into the system at required pressure and its flow is controlled by the solenoid valves. A total of four solenoid valves $(1,2,3 \& 4)$ are 
needed to put the system in a functional state, the valves operate in pairs of inlet and outlet each with $1 \& 4$ being the inlet valves and $2 \& 3$ being the outlet valves respectively. For optimum operation valve 1 pairs with valve 3 (inlet/outlet) and valve 4 pairs with valve 2 . For the purpose of this study, four feeding cycles have been adopted, lasting between the hours of 9:00am and 6:00pm at 3 hours interval. The operational cycles can be varied dependent on the availability of power supply and plant nutrient requirements. The air is pneumatically driven through the connecting pipes via the solenoid valve allowing the flow of air into the system. This is achieved by the use of programmeable timers which permits the flow of electric current at the designated periods. With this, pressurized air through the hydrophobic micropore filters is introduced into the bioreactor vessels, thus automating the system.
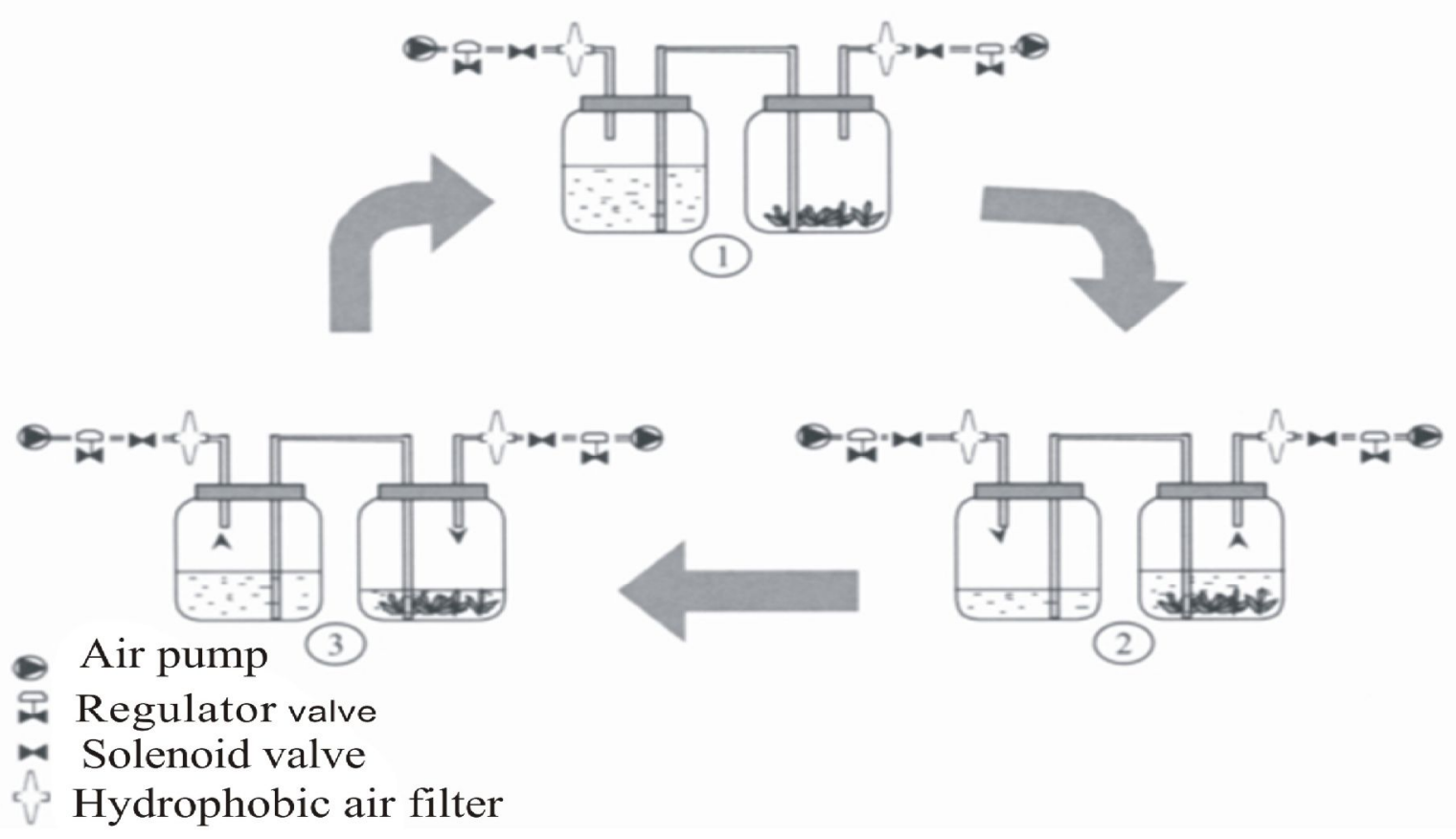

Figure 2. Schematic illustration describing the operation process of TIS following the given explanation

Source: Escalona (1999).

The system utilizes two culture vessels one containing the shoots and the second the liquid culture medium. Valve 3 (V3) is opened 10 secs prior to the opening of valve 1 (V1) to discharge excessive pressure in the system. This is to avoid damage or disconnection of connecting tubes and vessels resulting from high pressure. Pressurized air enters into bioreactor vessel A through the autoclaveable tube 1 at the opening of valve 1 . The air pressure in the vessel displaces the liquid medium through tube 2 . The pumping duration of the medium is also dependent on the quantity of medium in the bottle. It is important to note that excessive bubbling during the feeding cycle has been reported by Ziv (2000) to have a deterrent effect on plants in TIS. For use in this study a pumping duration of 2 minutes is employed during transfer of $250 \mathrm{ml}$ of medium from vessel A to vessel B. The period of immersion could also vary, based 


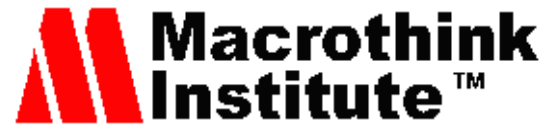

on specific plant requirements. The name of the system is basically derived from this process where plants are immersed temporarily, and again the immersion period depends on individual plant species under study.

After completion of the desired immersion period, a reverse process similar to the process explained above takes places again, this time around returning media to vessel A. Valve 2 (outlet) is opened and valve 4 is also opened 10secs later. This is accompanied by the inflow of pressurized air via tube 3, displacing the medium in vessel $\mathrm{B}$. The medium is withdrawn through tube 2 into vessel A. This cycle is continually repeated at the prescribed intervals ( 3 hours in this study) to ensure adequate nutrient uptake and nourishment of plants in TIS.
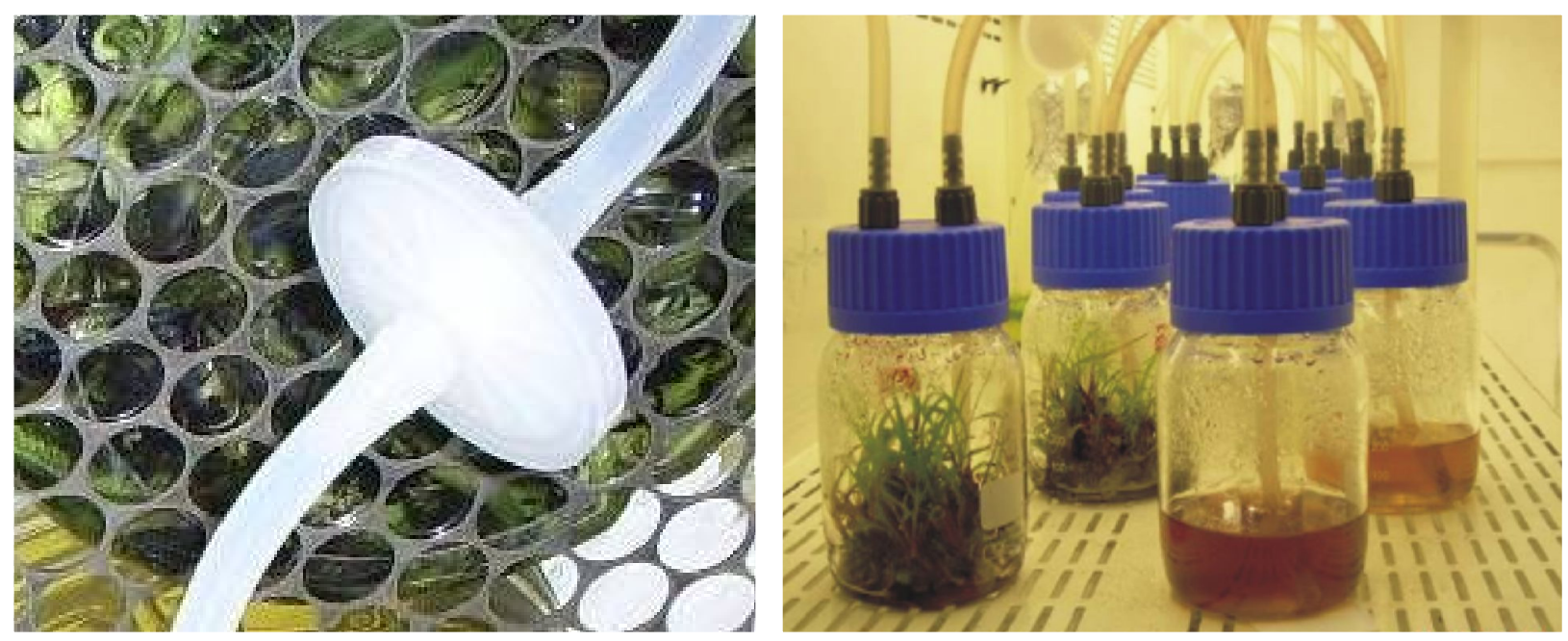

Figure 3: Accessories used in TIBs. Hydrophobic micropore filter of 0.22ul; Transparent vessel with cover of two holes and Connect tubing

Source: Aragon et al., 2009.

\section{Stages Involved in TIBs}

The process of plant micro-propagation aims to produce clones (true copies of a plant in large numbers). Four major stages are recommended for effective mass propagation of plant cultures using temporary immersion systems are subsequently explained.

3.1.1 Establishment of the mother explants on agar gel medium.

The establishment of truly aseptic cultures usually involves the following sequential steps:

Step I- Pre-propagation step or selection and pre-treatment of suitable plants.

This is the selection, screening and treatment of plants collected from the field before taking into the laboratory environment. The health status of the donor mother plant and of the plants multiplied from it are among the most critical factors, which determine the success of tissue culture operation. Hence, indexing of the mother plants for freedom from viral, bacterial, and fungal diseases is a normal procedure before undertaking propagation in large-scale plant propagation through tissue culture (Schmidt et al., 2002). This step is crucial as it tends to reduce the microbial load present at the time of collection and which may hinder or interfere 
with the in vitro processes. The plants upon treatment are observed in the green house for a short period of time before transfer into the laboratory. Pre-propagation step (also called stage 1) requires proper maintenance of the mother plants in the greenhouse under disease- and insect-free conditions with minimal dust. Clean enclosed areas, glasshouses, plastic tunnels, and net-covered tunnels, provide high quality explant source with minimal infection. Collection of plant material for clonal propagation should be done after appropriate pretreatment of the mother plants with fungicides and pesticides to minimize contamination in the in vitro cultures. This improves growth and multiplication rates of in vitro cultures. The control of contamination begins with the pretreatment of the donor plants. They may be prescreened for diseases, isolated and treated to reduce contamination (Martre, et al., 2001).

Step II - Initiation of explants - surface sterilization, establishment of mother explants.

This involves the sequential disinfection of the mother plant under aseptic conditions, culture initiation and establishment on a suitable growth media. The process requires excision of tiny plant pieces and their surface sterilization with chemicals such as sodium hypochlorite, ethyl alcohol and repeated washing with sterile distilled water before and after treatment with chemicals. The growth media is prepared in the preparatory room while the rest of the process is carried out under the laminar flow hood. The initiated cultures are then transferred to the growth room under controlled conditions of temperature, illumination and humidity for incubation. Initiation of explants is the very first step in micropropagation. A good clean explant, once established in an aseptic condition, can be multiplied several times; hence, explants initiation in an aseptic condition should be regarded as a critical step in micropropagation.

Step III - Subculture of explants on agar gelled media for multiplication and proliferation.

This involves the subculture of established explants on agar gelled media with a specific auxin/cytokinins combination to induce proliferation. In this step, explants are cultured on the appropriate media for multiplication of shoots. The primary goal is to achieve propagation without losing the genetic stability. Repeated culture of axillary and adventitious shoots, cutting of nodes, somatic embryos and other organs from Stage II lead to multiplication of propagules in large numbers. The propagules produced at this stage can be further used for multiplication by their repeated culture.

\subsubsection{Zero shelving of plants to liquid medium.}

Sometimes it is necessary to subculture the in vitro derived shoots onto different media for elongation and rooting for ex vitro transfer. However, if cultures must be mass propagated in Temporary Immersion System, they must be allowed to pass through the zero phase upon establishment and when they have gained a proliferation capacity/potential on the agar gelled multiplication media. This involves the gradual reduction of agar concentration in the nutrient medium from semi solid to liquid medium. This is usually done in order to prepare the explants for proper adaptation, survival and desired in vitro response in the next phase which utilizes only liquid medium. Zero shelving also gives room for proper check of microbial contamination that may be present in the culture and selection of healthy propagules prior to 


\section{MInstitute Macrothink $_{\text {Int }}$}

transferring into the temporary immersion systems. If contamination is noticed, the plantlets are retrieved and rescued. In situation whereby the contaminant persists, cultures are discarded. All other growth conditions are the same as mentioned earlier.

\subsubsection{Cultivation in Temporary Immersion Systems.}

This Phase refers to Plant cell and tissue development in the Temporary immersion bioreactors. It utilizes the advantages of liquid medium coupled with automated control of culture conditions to rapidly multiply explants thereby increasing exponentially the multiplication coefficient of the explants. The stage involves 3 major phases (Figure 4). They are:

- Multiplication phase

- Elongation phase

- Rooting and harvest

In vitro response of plantlets in each of the 3 phases of TIBs is highly dependent on certain factors including hormonal combination, duration of each feeding cycle and the overall timing/duration to which it is subjected to. eg. higher cytokinins (BAP) concentration to auxins in the multiplication media, Gibberillic acid (GA3) for elongation and auxins (IAA, NAA and IBA) for rooting. The timing to achieve goal at each phase varies depending on the individual species ability to respond to each phase accordingly. The common feature to all the phases is the use of liquid media (void of agar) to aid nutrient uptake and automation. Transfer of plantlets from one step to the next is carried out aseptically under the laminar flow hood. If the proliferated material consists of bud-like structures (e.g. orchids) or clumps of shoots (banana, pineapple), they should be separated after rooting and not before as this usually cause tissue wounding and stimulate the exudation of phenolic compound which interferes with the physicochemical factors that trigger root formation. This leads to malformed plants or plants with no roots. In this way, multiplied plantlets are elongated, rooted to produce complete plants and harvested. Harvest is carried out by an initial disinfection of the mouth of culture bottle with $1 \%$ Sodium hypochlorite. Bottle is opened and plantlets carefully collected.
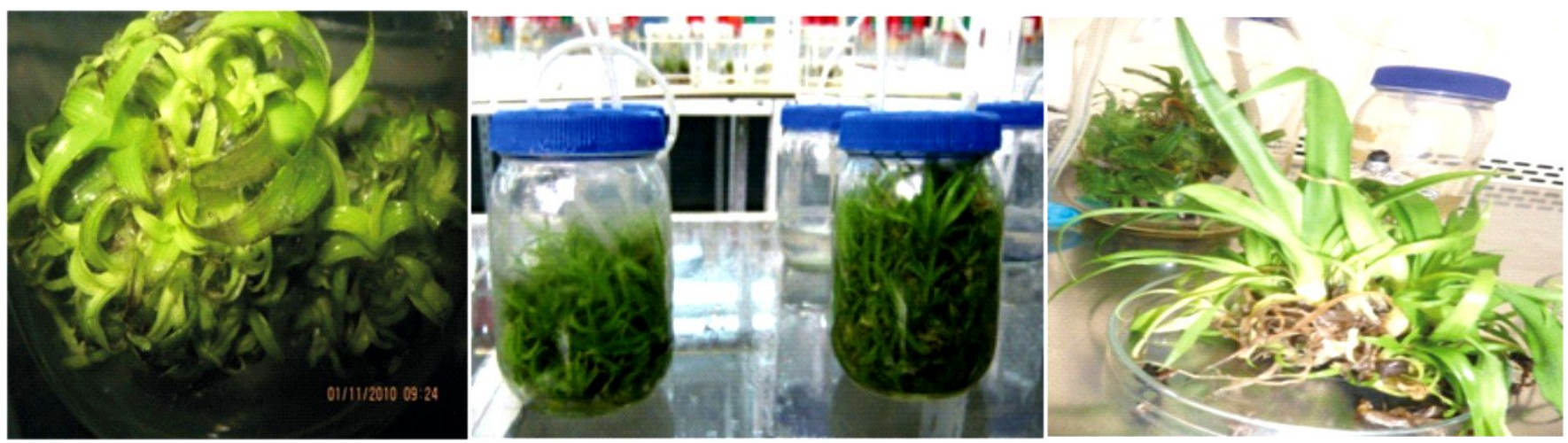

Figure 4: Multiplication ( $1^{\text {st }}$ picture showing proliferation in clusters); Elongation ( $2^{\text {nd }}$ picture showing stem growth elongation) and Rooting ( $3^{\text {rd }}$ picture clearly showing a developed root system) of pineapple in TIBs at NACGRAB

3.1.4 Acclimatization and Ex vitro transfer. 


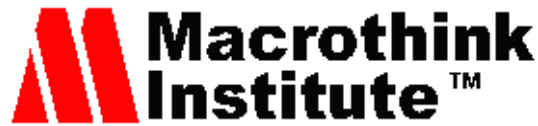

Journal of Biology and Life Science ISSN 2157-6076 2012, Vol. 3, No. 1

This is the final stage of the tissue culture operation including the use of bioreactor after which the micro propagated plantlets are ready for transfer to the greenhouse. Steps are taken to grow individual plantlets capable of carrying out photosynthesis. Collected plantlets are sorted and prepared for acclimatization based on their sizes and rooting capacity. In vitro micro propagated plants are weaned and hardened. The hardening of the bioreactor propagated plantlets is done gradually from high to low humidity and from low light intensity to high intensity conditions. Rooted plants are washed with tap water and acclimatized ex vitro on a medium composed of Coconut fibre, Top Soil and Stone dust mixed in the ratio 7:2:1 which can be left in shade for 3 to 6 days where diffused natural light conditions them to the new environment. The plants are then transferred to an appropriate substrate (sand, peat, compost, etc.), and gradually hardened. Low-cost options include the use of plastic domes or bags, which reduces the natural light intensity and maintains high relative humidity during the hardening process. If the plants are still joined together after rooting, these should be planted as bunches in the soil and separated after 6 to 8 weeks of growth.
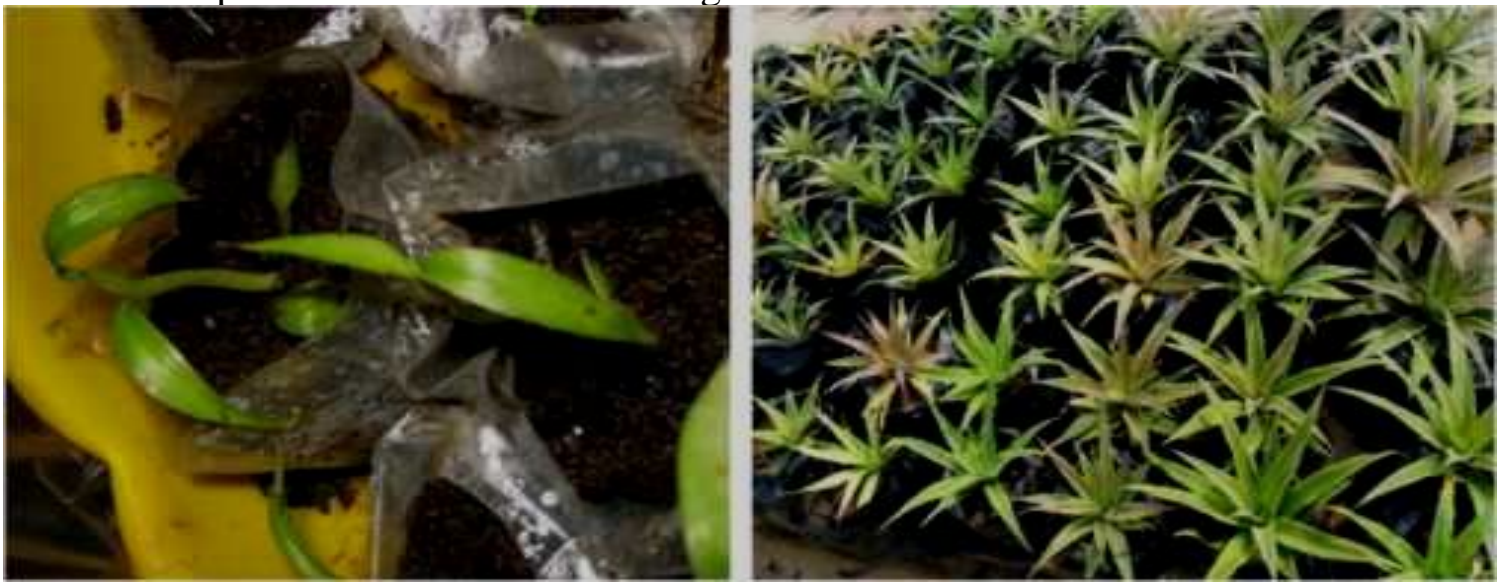

Figure 5: Potted and acclimatized TIBs base plants in the screen house at NACGRAB

These stages are universally applicable in large-scale multiplication of plants. The individual plant species, varieties and clones require specific modification of the growth media, weaning and hardening conditions. A rule of the thumb is to propagate plants under conditions as natural or similar to those in which the plants will be ultimately grown ex-vitro. Micropropagated plants must be subjected to an adequate duration of time required for their proper hardening.

\subsection{Growth Conditions in Temporary Immersion Bioreactors}

Conditions for growth and maintenance of in vitro cultures in Temporary Immersion Bioreactors include:

1. Natural and Artificial Photoperiod for cultures which should be 16 hours light per day.

2. Incubation Temperature $\left(20 \pm 2{ }^{\circ} \mathrm{C}\right)$.

3. The culture media which should have a $\mathrm{pH}$ of $5.7 \pm 1$ (that is to say 5.6-5.8 range). 
4. The culture media volume $(100-250 \mathrm{ml}$ for $500 \mathrm{ml}$ and $300-400$ for 1litrer capacity vessel).

5. Observation of 8 immersions per day with 3 hours interval. This condition is dependent on the plant species.

6. The duration of immersion of cultures in the media should range between $3-5$ minutes depending on the plant species.

7. Duration of the in vitro process:

Multiplication phase: - 4 -6weeks depending on the species.

Elongation phase: - 2 -3weeks and is species dependent.

Rooting phase: - 3-4 weeks.

Table 1: Some micro propagated plants using bioreactor

\begin{tabular}{|l|l|l|}
\hline \multicolumn{1}{|c|}{ Plant } & Propagule unit produced & \multicolumn{1}{c|}{ Reference } \\
\hline Amaryllis hippeastrum & Buds, bulblets. & Takayama and Akita, (1998) \\
\hline Apium graveolens & Somatic embryos & Nade et al., 1990. \\
\hline Ananas comosus. & Shoot clusters & --- \\
\hline Apium graveolens. & Somatic embryos. & Nade et al., 1990 \\
\hline Araceae species & Plants & Takayama and Akita, 1998. \\
\hline Acanthopanax koreanum. & Somatic embryos. & Son et al., 1999b \\
\hline Artemisa annua & Plants. & Park et al., 1989. \\
\hline Asparagus officinalis. & --- & Takayama, 1991. \\
\hline Begonia & Multiple shoots & Takayama and Misawa, 1981 \\
\hline Brodiaea species. & Bud clusters, corms & Ilan et al., 1995. \\
\hline Colocasia species. & --- & Takayama, 1991. \\
\hline Coffea arabica. & Shoot clusters, plants. & Teisson and Alard, 1995. \\
\hline Cyclamen persicum & Somatic embryos & Hvoslef-Eide and Munstar, 1998 \\
\hline Daucus carota & Somatic embryos & Jay et al., 1992. \\
\hline Dianthus caryophyllus & Shoots, plants. & Chatterjee et al., 1997. \\
\hline Digitalis lanata. & Somatic embryos. & Greidziak et al., 1990. \\
\hline Eschcholltzia californica. & Somatic embryos. & Archambault et al., 1994 \\
\hline Euphorbia puleherrima & Somatic embryos. & Preil, 1991. \\
\hline Fragaria ananasa & Shoots, plants. & Takayama and Akita, 1998. \\
\hline Gentiana species. & Plants. & Hosokawa et al., 1998. \\
\hline Gladiolus grandiflorum & Bud clusters, corms. & Ziv et al., 1994; Teisson and alvard, 1995. \\
\hline Gloximia & Shoots & Takayama, 1991 \\
\hline Hevea brasiliensis & Buds, plants & Alvard et al., 1993; Teisson and Alvard, 1995. \\
\hline Hyacinthus orientalis. & Bulblets, plants. & Takayama and Akita, 1998. \\
\hline
\end{tabular}




\begin{tabular}{|l|l|l|}
\hline Lilium species & Plants, bulblets & Takayama 1991. \\
\hline Medicago sativa & Somatic embryos. & Stuart et al., 1987. \\
\hline Musa species & Buds, plants & Alvard et al., 1993. \\
\hline Nephrolepts exaltata & Buds, plants & Levin et al., 1997; Ziv et al., 1998 \\
\hline Nerine sarniensis. & Bulblets, somatic embryos. & Lilien-Kipnis et al., 1994; Ziv et al., 1994 \\
\hline Ornithogalum dubium. & Shoots, bulblets, plans. & Ziv and Lilien Kipnis, 1997. \\
\hline Populus tremula. & Bud cluster, shoots. & McCown et al., 1988. \\
\hline Picea species & Somatic embryos. & Tautorus et al., 1994; Attree et al., 1994. \\
\hline Pinellia ternate. & Shoots, corm. & Takayama et al., 1991. \\
\hline Phalaenopsis. & Protocorm . & Young et al., 2000. \\
\hline Solanum tuberosum. & Clusters, shoots. & Takayama and Akita, 1998; Ziv et al., 1998. \\
\hline Stevia rebaudiana & Shoots & Akita et al., 1994 \\
\hline
\end{tabular}

Source: Mehrotra, 2007.

Table 2: Effect of Temporary Immersion Bioreactor (TIBs) On Biological Yield

\begin{tabular}{|l|l|l|l|}
\hline \multicolumn{1}{|c|}{ Crop } & \multicolumn{1}{|c|}{ Variety } & \multicolumn{1}{c|}{$\begin{array}{c}\text { Conventional } \\
\text { micropropagation }\end{array}$} & $\begin{array}{c}\text { Temporary } \\
\text { immersion systems }\end{array}$ \\
\hline Pineapple & Smooth cayenne & 8.0 & 68.8 \\
& MD2 & 5.8 & 26.8 \\
\hline Sugarcane & C91-301 & 3.7 & 34.1 \\
& C1051-73 & 4.1 & 58.0 \\
& C120-78 & 3.9 & 30.2 \\
& C323-68 & 4.3 & 39.5 \\
& Cp-5243 & 4.0 & 32.5 \\
\hline Taro & INIVIT & 3.0 & 10.4 \\
& Mexico 1 & 2.8 & 7.7 \\
\hline Banana & FHIA-18 & 3.8 & 7.4 \\
& FHIA-01 & 3.4 & 10.4 \\
& Grand Nane & 4.0 & 16.6 \\
\hline Plantain & CEMSA 3/4 & 2.5 & 7.8 \\
\hline Eucalyptus & Urograndis & 2.7 & 11.6 \\
\hline Syngonium & W. Butterfly & 7.3 & 28.0 \\
& Pixle & 2.2 & 18.4 \\
\hline Philodendron & xanadu & 2.0 & 8.8 \\
\hline Spathyphyllum & sensation & 3.7 & 17.6 \\
\hline
\end{tabular}

Source: Escalona, 2003.

\subsection{Challenges}

The use of liquid cultures in bioreactor for plant propagation imposes several problems such as leakage of endogenous growth factors, the need for an initial high concentration of the inoculum, lack of protocols and production procedures, increased hyperhydricity and malformation, foam development, shearing and oxidative stress, release of growth inhibiting 
compounds by the cultures and contamination. Unfortunately culture contamination which is a major problem in conventional commercial micropropagation is even more acute in bioreactors (Leifert and Waites, 1998). In conventional micropropagation, discarding a small number of the contaminated vessels is an acceptable loss; in bioreactors, even a single contaminated unit is a huge loss. However, despite these difficulties, a number of commercial laboratories have developed effective procedures to control contamination in bioreactors. Highlighted below are some of the challenges (Leifert and Waites, 1990; Leifert and Woodward, 1998; Leifert, 2000).

\subsubsection{Inadequate protocols and production procedures.}

Plant cultures in bioreactor required defined protocol to enhance efficiency and optimization. Lack of protocol for maintenance of cultures in bioreactors affects the potential scale up of plants especially for commercialization (Espinosa et al., 2002) Regeneration and initial establishment of cultures is more often accomplished on agar gelled medium. For scaling up plant production using bioreactors, in vitro protocols that can accommodate the proliferation of plant cultures in liquid medium needs to be developed. Protocols for proliferation on semi solid media are not always efficient when used in bioreactors. However, as no one protocol is utilized for all species, it becomes quite difficult to achieve success at a goal. Development of protocol for scaling up cultures in bioreactors entails extensive research and development in all phases of TIBs (multiplication, elongation and rooting). It is possible to record success at one phase and not overcome the challenges at the next phase. For the efficient scaling up of cultures in temporary immersion bioreactors for commercialization, protocol for multiplication, elongation and rooting must be developed.

\subsubsection{Increased hyperhydricity and malformation.}

The major disadvantage encountered when plants are cultured in liquid media is the problem of shoot malformation. Plants tend to accumulate excess of water in their tissue resulting to anomalous morphogenesis, a phenomenon known as Hyperhydricity. The plants that develop in liquid media are fragile, have a glassy appearance, with succulent leaves or shoots and a poor root system (Etienne, et al., 1997; Teisson, et al., 1995; Ziv, 1995). The leaves are the organs affected most severely in liquid cultures. They develop an unorganized mesophyll tissue that is made up mainly of spongy parenchyma tissue with large intercellular spaces (Etienne, et al. 2006), a deformed vascular tissue, and an abnormal epidermis. The epidermal tissue in hyperhydric leaves lacks a well developed cuticle and possesses malfunctioning guard cells which cannot respond to closure signals (Ziv et al. 1991; Ziv 1997; Ziv 2005). Hyperhydricity affects plant survival after transplanting and causes loss of the in vitro developed leaves, or even whole plants, which often wilt and die. The two major processes carried out by the leaves, photosynthesis and transpiration, are not fully functional in hyperhydric leaves and thus cause the poor performance of the transplanted plants ex vitro (Preece and Sutter 1991; Ziv, 1998., Ziv, 1995). In many plants propagated in vitro, the anomalous morphology and anatomical aberration often observed in plants result from deviation from the normal course of morphogenic events that are manifested in plants in vivo (Ammirato, 1985; Ziv, 2000).

The excessive accumulation of water in plant tissue (the most characteristic symptom of hyperhydricity) can also result in oxygen depletion in the cells, induce oxidative stress, 
production of reactive oxygen species (ROS) and cause injury to the plant tissue. Several developmental processes in tissue cultured plants can be affected by ROS leading to recalcitrance and loss of morphogenetic competence (Etienne, 2006). ROS such as $\mathrm{H} 2 \mathrm{O} 2$ and hydroxyl free-radicals react instantaneously with almost any substrates (Ziv, 2000). Attempts to control hyperhydric deformities have focused on better aeration and intermittent plant submergence in the medium, using temporary immersion bioreactors (Teisson, et al., 1996; Escalona, et al., 1999). Growth retardants have been used to reduce leaf expansion, thus minimizing shoot malformation. Some of the deformation, such as hyperhydric, malformed leaves and shoots, abnormal embryos, recurrent embryogenesis, and several other disorders (Ziv 1992, 1999, 2000), are apparently the result of interruption or faulty timing of the signals involved in the normal sequence of organizational events known to exist in vivo. These are problems that are manifested more severely in liquid medium and await further studies in order to understand and to help control plant morphogenic events in bioreactor cultures.

The following Suggestions have been known to reduce hyperhydricity problems in liquid media.

- Paper bridges or sponges (Escalona, et al., 2003).

- Double layer adding liquid medium to established culture on agar (Escalona, 1999).

- $\quad$ Mist Bioreactors (Teisson, et al., 1995).

- Temporary Immersion (Alvard, et al., 1993).

- A raft to support plants over stationary liquid (Hamilton et al., 1985).

\subsubsection{Problems of foaming, shear and oxidative stress.}

Growth and proliferation of the biomass in bioreactors depends on airflow supply for the aeration and mixing, and for the prevention of the plant biomass sedimentation. In many plants cultivated in bioreactors, continuous aeration, mixing, and circulation cause shearing damage, cell wall breakdown, and accumulation of cell debris, which is made up mainly of polysaccharides. Cell debris accumulation leads to the adhesion of cells and aggregates to the culture vessel walls which results in foaming and the development of a "crust" at the upper part of the bioreactor vessel. This layer prevents adequate liquid circulation and oxygen supply, causing additional cell debris formation and a demand for higher aeration rates that intensify the clogging problem (Scragg 1992). As the biomass increases and the cultures become viscous, higher rates of aeration are required to allow for oxygen supply and circulation. Several authors (Takayama, et al., 1991; Ziv, 1992; and Ziv 1998) have reported potential solutions to the problem of foaming and shear damage of tissues in bioreactors.

\subsubsection{Release of growth inhibiting compounds by the cultures.}

This is also known as the in vitro Phenolic browning or oxidation. The presence of phenolic compounds which cause death of explants has been another important problem of micropropagation especially in woody perennials ( $\mathrm{Ziv}, 2005$ ), in addition to various bacterial and fungal infection. Some of these exudates appear as a reaction to injury and/or infection. In 
tissue culture they appear after tissue excision and are many times aggravated by growth media constituents (Seneviratne and Wijesekara, 1996). Tissue blackening occurs due to action of copper-containing oxidase enzymes: polyphenoloxidases like tyrosinases, which are released or synthesized in oxidative conditions after tissue wounding and they oxidize O-diphenols released due to cellular wounding to o-quinones (Gamborg, 2002). The onset of tissue browning has been found to be associated with changes in protein pattern, amino acid content, ethylene production and the occurrence of saccharose and accumulation of starch (Fowler, 2000). These changes eventually lead to growth inhibition or death of explants. Other types of phenolic exudates appear at the end of incubation period and are apparently products of dying cells (Seneviratne and Wijesekara, 1996). The phenolic exudation is aided by light and is autocatalytic.

A number of methodologies have been employed to overcome phenolic oxidation in in vitro techniques. Some of them as suggested by Pierik, 1987; are as follows:

- Addition of activated charcoal $(0.2-3.0 \% \mathrm{w} / \mathrm{v})$ to the medium.

- Addition of polymeric polyvinylpyrrolidone (PVP) or polyvinylpolypyrrolidone (PVPP) to the medium. These absorb phenols through hydrogen bonding.

- Additions of anti-oxidants or reducing agents like citric and ascorbic acids, thiourea glutathione and L-cysteine in the medium or before surface sterilization. These reduce the redox potential of explants and stop the oxidation reactions (Marks and Simpson, 1990).

- Addition of diethyl-dithiocarbonate (DIECA) (2g.l-1) in the rinses after surface sterilization and as droplets at the time of micro grafting.

- Addition of amino acids like glutamine, arginine and asparagine to the media.

- Reduction of salt concentration in the growth media. Others may include:

- Frequent subcultures onto fresh media.

- Use of liquid medium for easier and quicker dilution of toxic products.

- Reduction of wounded tissues to decrease exudation.

- Soaking of explants in water before culturing to reduce browning.

- Incubation of fresh cultures in darkness for the first few days of culture.

Most of the suggested above have provided solution to phenolic oxidation in micropropagation and are widely employed in most laboratory across the globe.

\subsubsection{Microbial contamination}

Micropropagation techniques are extensively used for mass production of elite plants as well as to study the basic aspects of primary and secondary metabolism, morphogenesis and genetic engineering etc. But even after three decades of research and development in plant tissue culture, microbial contamination by yeasts, fungi, bacteria, viruses, mites and thrips is still the major problem that has hampered the establishment of truly aseptic plants and their successful Micro -propagation in bioreactors. The influence of bacteria on shoot growth can range from total inhibition to no apparent effect. The contaminating bacteria and fungi may be endophytic 
or epiphytic, pathogenic or saprophytic (Debergh and Maene, 1981, 1984). Another type of hazard for plant tissue and cell cultures is caused by 'latent' bacteria and viruses that do not produce any symptoms on the plant or any visible growth on the medium for long periods of time in vitro even after several subculture cycles. They reduce the multiplication rates and productivity of tissue cultures and may become 'virulent' at a later stage due to changes in incubation temperatures, growth medium composition and removal of antibiotics from the medium (Leifert and Waites, 1998). Increasing attention is being paid to ascertain sources of contamination, to develop procedures for their elimination by avoidance, rigorous manipulation of the nutritional and environmental conditions and by specific antibiotic treatments (DeFossard and DeFossard, 1988; Debergh and Read, 1991).

\subsection{Control of Contamination}

Prevention of contamination in bioreactors requires a proper handling of the plant material, equipment and cultures during transfers and production. Only the surface sterilized explants, multiplied in small vessels and indexed for freedom from diseases are used to initiate cultures in bioreactors. If the bioreactor is small, it is sterilized in an autoclavable plastic bag, sealed with a cotton wool plug, and opened only under the laminar flow cabinet. If the bioreactor is large, other methods to protect the vessel after autoclaving and during its transport to the sterile area must be provided. The vessel is assembled under laminar flow, taking care that non-sterile objects do not enter the sterile air stream in the vicinity of open ports. After inoculation, all the ports and covers are sealed and the bioreactor is brought to the growth room and connected to an air supply. For harvesting, the bioreactor is returned to the sterile area, and the ports or covers are opened so that the air stream cannot carry contamination from the outside. Despite the precautions taken in initiating cultures, bioreactors can become contaminated from the environment or from latent microbes in the culture. The contamination can be controlled with one or a combination of anti-microbial compounds, acidification of the media, and micro-filtration of the medium (Schmidt et al., 2004). While most of the fungal and bacterial diseases are eliminated during surface sterilization and culture, viruses survive through successive multiplication if the mother plant is infected (Sessitsch et al., 2002). Acidification of the medium ( $\mathrm{pH} 3$ ) has been used to control contamination in the multiplication of banana and in media for other crops (Leifert and Waites, 1998).

\section{Conclusion}

Bioreactors provide more precise control of the plant growth gaseous exchange, illumination, medium agitation, temperature and $\mathrm{pH}$ than the conventional culture vessels. Bioreactor based propagation of plants can increase rate of multiplication, growth of cultures, reduce space, energy and labour requirements in commercial micropropagation. They can therefore, be attractive to developing countries with regards to new or expanding plant tissue culture facilities, in combination with a conventional laboratory. However, to be cost- effective, use of bioreactors requires indexed plant cultures, and attention to aseptic procedures during handling of plant materials. Hence, the integration of bioreactors into production systems should only be attempted by facilities with skilled and experienced expertise because such systems involve more risks, associated with inherently difficult problems of contamination in liquid systems. 
Temporary immersion bioreactors (TIBs) has the potential to boost the Nigerian economy by scaling up the production process and at the same time fulfilling the aspirations of the huge populace especially as regards food security.

\section{References}

Adelberg, J.W. and Simpson, E.P. (2002). Intermittent Immersion Vessel Apparatus and Process for Plant Propagation. Internl. S/N: PCT/US01/06586.

Aitken-Christie, J. (1995). Automation in plant tissue culture-general introduction and overview. In: Automation and Environmental Control in Plant Tissue Culture., J. Aitken-Christie, T. Kozai and M.A.L. Smith (Editors). Kluwer Academic Publisher, Dordrecht, Netherland. Pp 1- 12.

Alvard, D., Cote, F. and Teisson, C. (1993). Comparison of methods of liquid medium culture for banana micropropagation. Plant Cell, Tissue Organ Culture, 32:55-60. http://dx.doi.org/10.1007/BF00040116

Ammirato, P. V. and Styer, D.J. (1985). Strategies for large scale manipulation of somatic embryos in suspension culture. In: Biotechnology in plant science: Relevance to agriculture in the eighties, Zaitlin, M., Day, P. and Hollaender, A. (Editors), Academic Press, New York. Pp. 161-178

Ammirato, P.V, Evans, D.A, Sharp, W.R, and Bajaj, Y.P (1985). Handbook of plant cell culture: Ornamental species. 5th edition, McGraw Hill, Yew York. 31Pp.

Christianson, M. L. (1985). An embryogenic culture of soybean: towards a general theory of somatic embryogenesis In: Tissue culture in forestry and agriculture. Henke, R.T., Hughes, K.W., Constantin, M.J and Hollaender (Editors). Plenum Press, New York. . p. 83-103.

Christianson, M. L. (1987). Causal events in morphogenesis. In: Plant tissue culture. Green, C.E., Sommers, D.A., Hackett, W.P. and Biesboer, D.D. (Editors). Allan R. Liss, New York. p. 45-56.

Deberge, P.C and Maene, L.J. (1981). A scheme for commercial propagation of ornamental plants by tissue culture. Scientia Horticulturae., 14: 335-345. http://dx.doi.org/10.1016/0304-4238(81)90047-9

Debergh, P.C. and Read, P.E. (1991). Micropropagation. In: Micropropagation Technology and Application. Debergh, P.C, and Zimmerman, R.H. (Editors). Kluwer Academic Pulishers,Dordrecht, pp. 1-13.

De Fossard, R.A. and De Fossard, H. (1988). Coping with microbial contaminants and other matters in a small commercial micropropagation laboratory. Acta Horticulturae, 225: 167176.

Escalona, M., Lorenzo, J.C., Gonzales, B.L., Daquinta, M., Borroto, C.G., Gozales, J.I. and Desjardine, Y. (1999). Pineapple (Ananas comosus L. Merr.) micropropagation in temporary 
immersion system. Plant Cell Report, $\quad$ (18): 743-748. http://dx.doi.org/10.1007/s002990050653

Escalona, M., Samson, G., Borroto, C. and Desjardins, Y. (2003). Physiology of Effects of Temporary Immersion Bioreactors on Micropropagated Pineapple Plantlets. In Vitro Cell Developmental Biology of Plant, (39): 651-656. http://dx.doi.org/10.1079/IVP2003473

Espinosa, P., Lorenzo, J.C., Iglesias, A., Yabor, L., Menéndez, E., Borroto, J., Hernández, L. and Arencibia, A.D. (2002). Production of pineapple transgenic plants assisted by temporary immersion bioreactors. Plant Cell Report, (21): 136-140

Etienne, H., Lartaud, M., Michaux-Ferrie`re, N., Carron, M.P., Berthouly, M. and Teisson, C. (1997). Improvement of somatic embryogenesis in Hevea brasiliensis (Mu“ 11. Arg.) using the temporary immersion technique. In Vitro Cellular and Developmental Biology of Plant, (33): 81-87. http://dx.doi.org/10.1007/s11627-997-0001-2

Etienne, H., Dechamp, E., Etienne, B.D. and Bertrand, B. (2006). Bioreactors in coffee micropropagation. Brazilian Journal of Plant Physiology, (18): 2-3.

Fowler, M. R. (2000). Plant cell culture, laboratory techniques. In: Encyclopedia of cell technology, Spier, R.E (Editor), Wiley, New York. Pp. 994-1004.

Gamborg, O. L. (2002). Plant tissue culture. Biotechnology. Milestones. In vitro Cellular and Developmental Biology—Plant, (38): 84-92. http://dx.doi.org/10.1079/IVP2001281

Leathers, R.R., Smith, M.A. and Aiken-Christie, J. (1995). Automation of bioreactor process for mass propagation and secondary metabolism. In: Automation and environmental control in plant tissue culture. Kluwer Academic Publishers, Dordrecht. Pp 187-214.

Leifert, C. and Waites, W.M. (1990). Contaminants of plan tissue culture. Internl. Assoc. Plant Tiss. Cult. Newsl. (60): 2-13.

Leifert, C., and Waites, W. M. (1998). Bacterial growth in plant tissue culture. Journal of Applied Bacteriology, (72):460-466.

Leifert, C. and Woodward, S. (1998). Laboratory contamination management: the requirement for microbiological quality assurance. Plant Cell Tiss. Org. Cult, (52): 83-88.

Leifert, C. (2000). Quality Assurance Systems for Plant Cell and Tissue Culture: The problem of Latent Persistance of Bacterial Pathogens and Agrobacterium Transformed vector systems. In. Proceedings of the International Symposium, methods and markers for quality assurance in micropropagation. A.C. Cassells et al. (Eds.) Acta. Horticulturae. Pp. 530.

Levin R, Gaba V, Tal B, Hirsch S, Denola D, Vasil I.K. (1988). Automated plant tissue culture for mass propagation. Biotechnology, (6): 1035-1040.

Levin, R., Stav, R., Alper, Y. and Watad, A.A. (1998). A technique for repeated non-axenic subculture of plant tissues in a bioreactor on liquid medium containing sucrose. Plant Tissue Culture Biotechnology, (3):41-45. 
Marks, T.R. and Simpson, S.E. (1990). Reduced phenolic oxidation at culture initiation in vitro following the exposure of field grown stock plants to darkness or low level irradiation. Journal of horticultural science, (65):103-111.

Martre, P., Lucan, D., Just, D. and Teisson, C. (2001). Physiology of effects of Temporary Immersion on Hevea brasiliensis callus. Plant cell tissue organ culture, (67): 25-35. http://dx.doi.org/10.1023/A:1011666531233

Mehrotra, S., Manoj, K.G., Arun, K. and Bhartendu, N. M. (2007). Efficiency of liquid culture systems over conventional micropropagation: A progress towards commercialization. African Journal of Biotechnology, 6 (13): 5-6.

Pierik, R.L.M. (1987). In Vitro Culture of Higher Plants. Kluwer Academic Pulishers, Dordrecht, pp. 25-33. http://dx.doi.org/10.1007/978-94-009-3621-8

Preil, W., Florek, P., Wix, U. and Beck, A. (1988). Towards mass propagation by use of bioreactors. Acta Horticulturae, (226):99-106.

Preil, W. (1991). Application of bioreactors in plant propagation. In: Micropropagation: Technology and application. Debergh, P.C. and Zimmerman, R.H (Editors.), Kluwer Academic Publishers, Dordrecht, The Netherlands. Pp. 425-455.

Preece, J. E., and Sutter, E. (1991). Acclimatization of micropropagated plants to the greenhouse. In: Micropropagation: Technology and application. Debergh, P.C. and Zimmerman, R.H (Editors), Kluwer Academic. Publishers., Dordrecht, The Netherlands. p. 71-91.

Schmidt, J. Wilhem E. and Savangikar,V.A. (2002). Disease detection and elimination. In: Low cost options for tissue culture technology in developing countries. Proceedings of a Technical Meeting, Joint FAO/IAEA Division of Nuclear Techniques in Food and Agriculture. $\operatorname{Pg}$ 55-61.

Scragg, A. H. (1992). Large-scale plant cell culture: methods, applications and products. Current Opinion Biotechnology, 3:105-109. http://dx.doi.org/10.1016/0958-1669(92)90136-7

Seneviratne, P. and Wijesekara, G.A.S (1996). The problem of phenolic exudates in in vitro cultures of mature Hevea brasiliensis. Journal of Plantation Crops, 24(1):54-62.

Sessitsch, A., Reiter, B., Pfeifer, U. and Wilhelm, E. (2002). Cultivation-independent population analysis of bacterial endophytes in three potato varieties based on eubacterial and Actinomyces-specific PCR of 16rRNA genes. FEMS Microb. Ecol., 39: 23-32. http://dx.doi.org/10.1111/j.1574-6941.2002.tb00903.x

Steward, F. C., Ammirato, P. V. and M. O. Mapes. (1970). Growth and development of totipotent cells; some problems, procedures and perspectives. Annual Botany, 34:761-787.

Takayama, S., Swedl, B. and Miwa, Y. (1991). Automated propagation of microbulbs of lilies. In: Cell culture and somatic cell genetics of plants., Vasil, I.K. (Editor), Vol.8. Academic Press, New York. Pp. 111-131. 


\section{Al Macrothink}

Journal of Biology and Life Science

ISSN 2157-6076 2012, Vol. 3, No. 1

Takayama, S. and Akita, M. (1994). The types of bioreactors used for shoots and embryos. Plant Cell, Tissue and Organ Culture, (39): 147-156. http://dx.doi.org/10.1007/BF00033922

Tautorus, T. E., and Dunstan, D. I., (1995). Scale-up of embryogenic plant suspension cultures in bioreactors. In: Somatic embryogenesis in woody plants. Jain, M. Gupta, P.K and Newton, R.J. (Editors), Vol.1. Kluwer Academic. Publisher., Dordrecht, The Netherlands. p. 265-269.

Teisson, C. and Alvard, D. (1995). A new concept of plant in vitro cultivation in liquid medium: Temporary Immersion. In: Current Issues in Plant Molecular and Cellular Biology. Terzi, M., Cella, R. and Falavigna, A. (Editors). Kluwer Academic Publisher pp 105-109. http://dx.doi.org/10.1007/978-94-011-0307-7_12

Weathers, P. J., Dilorio, A. and Cheetham, R. D. (1989). A bioreactor for differentiated plant tissues. Proceedings of Biotechnoly. USA SF Conference. 247-256.

Ziv, M. (1991a). Morphogenic pattern of plants in liquid medium in shaken flasks or large scale bioreactor cultures. Israel Journal of Botany. (40): 145-153.

Ziv, M. (1991b). Quality of micropropagated plants: Vitrification. In vitro Cell Developmental Biology of Plant (27): 64-69. http://dx.doi.org/10.1007/BF02632130

Ziv, M. and Ariel, T. (1991c). Bud proliferation and plant regeneration in liquid-cultured philodendron treated with ancymidol and paclobutrazol. Journal of Plant Growth Regulators. (10): 53-57. http://dx.doi.org/10.1007/BF02279311

Ziv, M. (1992). Morphogenic control of plants micropropagated in bioreactor cultures and its possible impact on acclimatization. Acta Horticulturae. 319: 119-124.

Ziv, M. (1995). The control of bioreactor environment for plant propagation in liquid culture. Acta Horticulturae. (393): 25-38.

Ziv, M. and Lilien, K.H. (1997). Bud cluster proliferation and bulb formation from bioreactor cultures of Ornithogalum dubium. Acta Horticulturae., 430: 307-310.

Ziv, M., Ronen, G. and Raviv, M. (1998). Proliferation of meristematic clusters in disposable presterlized plastic bioreactors for large scale micropropagation of plants. In vitro Cell Developmental Biology of Plant. (34): 152-158. http://dx.doi.org/10.1007/BF02822781

Ziv, M. (2000). Bioreactor technology for plant micropropagation. Horticultural Review, (24): $1-30$.

Ziv, M. (2005). Simple bioreactors for mass propagation of plants. Plant Cell Tissue Organ Culture, (81): 277-285. http://dx.doi.org/10.1007/s11240-004-6649-y

\section{Copyright Disclaimer}

Copyright reserved by the author(s).

This article is an open-access article distributed under the terms and conditions of the Creative Commons Attribution license (http://creativecommons.org/licenses/by/3.0/). 